\title{
Epidemiology, Clinical Profile and Outcome of Patients of Snake Bite in Mymensingh Medical College Hospital
}

\author{
MT MIAH ${ }^{\mathrm{a}}$, AA HOQUE ${ }^{b}$, BK TARAFDER ${ }^{\mathrm{c}}$, MKH PATWARY $^{\mathrm{d}}$, RR KHAN ${ }^{\mathrm{d}}$, SMEJ KABIR ${ }^{\mathrm{d}}$
}

\begin{abstract}
Summary:
Snake bite is a serious global health problem. Incidence is high in Bangladesh and mortality is identified to be one of the highest in the world. Most bites are occurred by nonpoisonous snakes and as many as $40 \%$ bites inflicted by venomous snakes do not produce features of envenoming. They need supportive treatment only. Poisonous bites are treated with antivenin. But most people apply tight tourniquet and take useless and harmful treatment from traditional healers before getting admitted in hospital. Delay in diagnosis and treatment causes fatality in many cases. 46 patients admitted in department of Medicine, MMCH from April,07 to March,08 with snake bites were studied. Among them 35\% were poisonous and $65 \%$ were nonpoisonous bites. Male and female ratio was 3.6:1. Mean age (years) was $34.9 \pm 16.2$ SD. Mean time of interval between bite and hospitalization (hours) was $7.8 \pm$ 9.5 SD. $94 \%$ bites occurred in land and $7 \%$ in water. $100 \%$
\end{abstract}

Introduction:

Snake bite is one of the significant causes of global morbidity and mortality. It has been estimated that 5 million snake bite cases occur worldwide every year, causing about 100,000 deaths. ${ }^{1}$ In Bangladesh adequate data is not available due to lack of systematic record keeping system and lack of information and awareness at community level. An epidemiological study estimated the incidence of snake bites in Bangladesh about 8000 per year with $22 \%$ mortality $^{2}$ which has been identified to be one of the highest in the world. Bangladesh supports

a. Dr. Md. Titu Miah, Junior Consultant, Medicine Unit-4, Mymensingh Medical College Hospital.

b. Dr. Akm Aminul Hoque, Associate Professor, Medicine unit4, Mymensingh Medical College Hospital

c. Dr. Binoy Krishna Tarafder, Assistant Registrar, Medicine unit-4, Mymensingh Medical College Hospital.

d. Dr. Md. Kamal Hossain Patwary, Dr. Raihan Rotap Khan, Dr. Shah Mohd. Eftar Jahan Kabir, IMO, Medicine unit-4, Mymensingh Medical College Hospital.

Address of correspondence: Dr. Md. Titu Miah, Junior Consultant, Medicine Unit-4, Mymensingh Medical College Hospital.

Received: 12 May, 2008

Accepted: 2 January, 2009 patients applied multiple tourniquets in the affected limb. $24 \%$ patients received treatment from traditional healers with development of cellulitis in $64 \%$ of them. None received proper first aid management. Most incidences were in July - August. Snakes could not be identified in $50 \%$ poisonous and $77 \%$ non-poisonous cases. Among the identified poisonous snakes, kraits were $84 \%$. Clinical features were also suggestive of krait bite in $88 \%$ poisonous cases. Among poisonous cases, $94 \%$ presented with neurological manifestation and ptosis was present in all of them. $75 \%$ poisonous snake-bite patients received antivenin and none of them developed anaphylaxis. Among 4 poisonous snake bite patients who did not receive antivenin, 2 survived. Mortality in poisonous cases was $44 \%$. All of the non-poisonous cases improved with supportive treatment.

(J Bangladesh Coll Phys Surg 2009; 27: 70-75)

approximately 80 species of snakes. ${ }^{3-6}$ Among them only few are venomous. These are Cobra, Krait, Russel's viper, Saw scaled viper, green snakes, sea snakes. Most bites are occurred by non-poisonous snakes and as many as $40 \%$ bites inflicted by venomous snakes do not produce signs of envenoming. Bites usually result from an unfortunate accidental interaction between a snake and a human victim. It occurs mostly when the people are at work like cultivation, gardening, plantation, wood collection, watching the crops even during walking. However bites are fairly common when victims are at sleep. Snake bite is a horrifying experience for the victim. During the bite it is unlikely that people can identify the offending snake. They may think that every bite could result in fatality. Venomous snake bites can be presented with local or systemic features of envenoming-neurological, haematotoxicities, myotoxicities, organ failure and some nonspecific features. Frequently victims present with complication of treatment by traditional healers or self induced inappropriate application of tourniquet. As for centuries people are used to take treatment from traditional healers, ohzas who demonstrate a number of rituals which are useless and harmful. The mainstay of management is anti-snake venom which although 
effective, can cause anaphylaxis. So at primary level hospital, it is usually withheld despite indication for possible danger which is easy to manage with proper approach. ${ }^{7,8}$ Only supportive treatment including tetanus prophylaxis and assurance is sufficient for non-poisonous bites. The interval between the bite and death is $<6$ hours in most cases. ${ }^{9}$ So delay in diagnosis and treatment causes fatality.

\section{Materials and Methods:}

This is an observational study done in the department of Medicine, Mymensingh Medical College Hospital from $1^{\text {st }}$ April, 2007 to $31^{\text {st }}$ March, 2008. Patients aged 13 years and above admitted with the suspicion of snake bite during the period were identified. Among them, those who saw snakes or in whom bite mark or scratch mark were present or those who developed features of envenomation were diagnosed as snake bite cases. Patients with local or systemic features of envenomation according to the 'National Guideline of Management of Snake Bite' were detected as poisonous snake bite cases and types of snakes were also suspected accordingly. 20 minutes whole blood coagulation test were done in all patients. Other investigations were done according to same guideline. Data were collected in a specific format and analyzed subsequently.

\section{Results:}

With suspicion of snake bite more than 250 patients were admitted during the study period. Only 46 (less than $18 \%$ ) of them were identified as both poisonous and non-poisonous snake bite. Among them 16 (35\%) were poisonous who had clinical features of envenomation and $30(65 \%)$ were non-poisonous who did not have any feature of envenomation.

$100 \%$ patients applied multiple tight tourniquets in the affected limb. Short term complication happened to none of them. 11 patients $(24 \%)$ received treatment from traditional healers. Among them 7 developed cellulitis (64\%). None of them received first aid management. 43 (94\%) bites occurred in land, 16 were poisonous $(37 \%) \& 27$ were nonpoisonous (64\%). 3 (7\%) were in water, all were nonpoisonous.

15 patients $(94 \%)$ presented with neurological manifestation with ptosis in all of them $(100 \%)$ and in 14 of them no other local or systemic features were present. 2 patients came with local features of envenomation, 1 associated with bleeding manifestation and the other with features of neurotoxicities.

12 patients $(75 \%)$ received antivenin and none developed anaphylaxis due to antivenin.

All patients including non-poisonous bites received supportive treatment including tetanus prophylaxis.

Table-I

Characteristics of snake bite cases

\begin{tabular}{ll}
\hline Non-poisonous: Poisonous & $1.9: 1$ \\
Male: Female & $3.6: 1$ \\
Mean age (yrs) & $34.9 \pm 16.2 \mathrm{SD}$ \\
Mean time of interval between bite \& hospitalization (hrs) & $7.8 \pm 9.5 \mathrm{SD}$ \\
Mortality in poisonous cases & $44 \%$ (approximately)
\end{tabular}

Table-II

Age distribution of snake bite patients $(n=46)$

\begin{tabular}{lccc} 
Age group ( yrs) & $\begin{array}{c}\text { Poisonous } \\
(\% \text {-approximately) }\end{array}$ & $\begin{array}{c}\text { Non-poisonous } \\
(\% \text {-approximately) }\end{array}$ & $\begin{array}{c}\text { Total } \\
(\% \text {-approximately) }\end{array}$ \\
\hline $13-20$ & $02(04 \%)$ & $09(20 \%)$ & $11(24 \%)$ \\
$21-30$ & $04(09 \%)$ & $09(20 \%)$ & $13(28 \%)$ \\
$31-40$ & $06(13 \%)$ & $02(04 \%)$ & $08(17 \%)$ \\
$41-50$ & $02(04 \%)$ & $05(11 \%)$ & $07(15 \%)$ \\
$51-60$ & $01(02 \%)$ & $02(04 \%)$ & $03(07 \%)$ \\
$>60$ & $01(02 \%)$ & $03(07 \%)$ & $04(09 \%)$ \\
\hline Total & $16(35 \%)$ & $30(65 \%)$ & $46(100 \%)$ \\
\hline
\end{tabular}




\section{Table-III}

Gender variation in snake bite patients $(n=46)$

\begin{tabular}{lccc} 
Sex & $\begin{array}{c}\text { Poisonous } \\
(\% \text {-approximately) }\end{array}$ & $\begin{array}{c}\text { Non-poisonous } \\
(\% \text {-approximately })\end{array}$ & $\begin{array}{c}\text { Total } \\
(\% \text {-approximately })\end{array}$ \\
\hline Male & $12(26 \%)$ & $24(52 \%)$ & $36(79 \%)$ \\
Female & $04(9 \%)$ & $06(13 \%)$ & $10(22 \%)$ \\
\hline Total & $16(35 \%)$ & $30(65 \%)$ & $46(100 \%)$ \\
\hline
\end{tabular}

\section{Table-IV}

Time passed before admission of snake bite patients

\begin{tabular}{|c|c|c|c|c|c|}
\hline \multirow[t]{2}{*}{ Hour } & \multicolumn{2}{|c|}{ Poisonous $(\mathrm{n}=16)$} & \multicolumn{2}{|c|}{ Non-poisonous $(\mathrm{n}=30)$} & \multirow{2}{*}{$\begin{array}{c}\text { Total }(\mathrm{n}=46) \\
(\% \text {-approximately) }\end{array}$} \\
\hline & $\begin{array}{l}\text { Improved (\%- } \\
\text { approximately) }\end{array}$ & $\begin{array}{c}\text { Died (\%- } \\
\text { approximately) }\end{array}$ & $\begin{array}{l}\text { Improved (\%- } \\
\text { approximately) }\end{array}$ & $\begin{array}{c}\text { Died (\%- } \\
\text { approximately) }\end{array}$ & \\
\hline $0-6$ & $03(19 \%)$ & $01(06 \%)$ & $25(83 \%)$ & $00(00 \%)$ & $29(63 \%)$ \\
\hline$>6-24$ & $05(31 \%)$ & $06(38 \%)$ & $05(17 \%)$ & $00(00 \%)$ & $16(35 \%)$ \\
\hline$>24$ & $01(06)$ & $00(00 \%)$ & $00(00 \%)$ & $00(00 \%)$ & $01(02 \%)$ \\
\hline Total & $09(56 \%)$ & $07(44 \%)$ & $30(100 \%)$ & $00(00 \%)$ & $46(100 \%)$ \\
\hline
\end{tabular}

Table-V

\section{Monthly variation in occurrence of snake bites $(n=46)$}

\begin{tabular}{lccc} 
Month & $\begin{array}{c}\text { Poisonous } \\
(\% \text {-approximately) }\end{array}$ & $\begin{array}{c}\text { Non poisonous } \\
(\% \text {-approximately) }\end{array}$ & $\begin{array}{c}\text { Total }(\mathrm{n}=46) \\
(\% \text {-approximately) }\end{array}$ \\
\hline 7-Apr & $00(00 \%)$ & $03(07 \%)$ & $03(07 \%)$ \\
7-May & $00(00 \%)$ & $04(09 \%)$ & $04(09 \%)$ \\
7-Jun & $03(07 \%)$ & $01(02 \%)$ & $04(09 \%)$ \\
7-Jul & $03(07 \%)$ & $14(30 \%)$ & $17(37 \%)$ \\
7-Aug & $03(07 \%)$ & $05(11 \%)$ & $08(17 \%)$ \\
7-Sep & $02(04 \%)$ & $01(02 \%)$ & $03(07 \%)$ \\
7-Oct & $03(07 \%)$ & $01(02 \%)$ & $04(09 \%)$ \\
7-Nov & $01(02 \%)$ & $00(00 \%)$ & $01(02 \%)$ \\
7-Dec & $00(00 \%)$ & $00(00 \%)$ & $00(00 \%)$ \\
8-Jan & $00(00 \%)$ & $00(00 \%)$ & $00(00 \%)$ \\
8-Feb & $00(00 \%)$ & $00(00 \%)$ & $00(00 \%)$ \\
8-Mar & $01(02 \%)$ & $01(02 \%)$ & $02(04 \%)$ \\
\hline Total & $16(35 \%)$ & $30(65 \%)$ & $46(100 \%)$
\end{tabular}




\section{Table-VI}

\section{Type of snakes identified by the victims}

\begin{tabular}{lcc} 
& Feature of envenomation $(\mathrm{n}=16)$ & No Feature of envenomation $(\mathrm{n}=30)$ \\
\hline Krait & $05(31 \%)$ & $00(00 \%)$ \\
Cobra & $01(06 \%)$ & $00(00 \%)$ \\
Others & $00(00 \%)$ & $07(44 \%)$ \\
Unidentified & $08(50 \%)$ & $23(77 \%)$ \\
Not seen & $02(13 \%)$ & $00(00 \%)$ \\
\hline Total & $16(100 \%)$ & $30(100 \%)$
\end{tabular}

Table-VII

\begin{tabular}{lccc}
\multicolumn{3}{c}{ Clinical manifestations of poisonous snake bite cases $(n=16)$} & \\
Features & $\begin{array}{c}\text { Died } \\
(\% \text {-approximately })\end{array}$ & $\begin{array}{c}\text { Improved } \\
(\% \text {-approximately) }\end{array}$ & $\begin{array}{c}\text { Total } \\
(\%-\text {-approximately) }\end{array}$ \\
\hline Neurotoxic & $07(44 \%)$ & $08(50 \%)$ & $15(94 \%)$ \\
Haemotoxic & $01(06 \%)$ & $00(00 \%)$ & $01(06 \%)$ \\
Myotoxic & $00(00 \%)$ & $00(00 \%)$ & $00(00 \%)$ \\
Organ failure & $03(19 \%)$ & $02(13 \%)$ & $05(31 \%)$ \\
Non specific & $04(25 \%)$ & $08(50 \%)$ & $12(75 \%)$ \\
Local sign & $01(06 \%)$ & $01(06 \%)$ & $02(13 \%)$ \\
20 min WBCT positive & $00(00 \%)$ & $01(06 \%)$ & $01(06 \%)$
\end{tabular}

\section{Table-VIII}

\section{Treatment response with antivenin}

\begin{tabular}{lcc} 
Antivenin & Improved (\% -approximately) & Died (\%-approximately) \\
\hline Given $(\mathrm{n}=12)$ & $07(58 \%)$ & $05(42 \%)$ \\
Not given $(\mathrm{n}=04)$ & $02(50 \%)$ & $02(50 \%)$ \\
\hline
\end{tabular}

\section{Discussion:}

Though many patients were admitted in hospital with suspicion of bitten by snakes, most of them were not at all cases of snake bite. Among the snake bite cases, most are nonpoisonous (65\%) which is consistent with other studies 10 and need supportive and symptomatic treatment only. People of younger age group are affected in majority of cases. Males (79\%) are mostly victimized. These are reflected in other studies also. Both are may be due to involvement of more outdoor activities of these groups. There was seasonal variation of the incidences of snake bites being mostly occurred in July-August and least incidences were in November-March which is almost similar to the result of study done in the northern area of Bangladesh. ${ }^{10}$ This may be due to habitat of snake and environmental factors like rainy season, flood etc. In most cases snakes were seen but not identified which is not only true for our population but also for the Australian. ${ }^{11}$ Probable cause may be, victims and 
the bystanders remain in a panic state and may be most of the people have little knowledge about types of snakes. Studies about types of snake is inadequate but a survey of $10 \%$ of the country in $1988-9$ reveals Cobra bites was $34 \%$ of all bites ${ }^{12}$ and cobra had been found to be the commonest poisonous snake in Chittagong ${ }^{13}$ also. In present study, among the 6 identified poisonous snakes, Kraits were the culprit in majority cases $(83 \%)$ and clinical manifestations were also suggestive of krait bite in most cases (14 out of 16) reflecting the predominance of this species in this region. After the bites, all applied tight tourniquet to their limbs which were not done in appropriate method and may lead to serious complications to patients though fortunately none in this study population developed so. The incidence of taking useless and harmful treatment from traditional healers are not very much high in this study in comparison to other studies which is a good sign and reflects the awareness of people about it. But those who took it, most suffered from complication like cellulitis. The alarming fact is that none received any proper first aid management even in primary level hospital. All of the poisonous snake bite occurred in land and in case of bite in water, all were nonpoisonous, though the number of cases were too small to comment. Most of the poisonous cases (75\%) came after 6 hours of bite and 38\% died. Those who came within 6 hours $(25 \%)$ were mostly improved $(19 \%)$. Only one patient whose features of envenomation appear after 24 hours and came after 2 days, survived without receiving antivenin. Analysis of features of envenomation shows neurotoxic features in $94 \%$ cases and ptosis was present in all of them which is higher than other studies. ${ }^{10}$ And in $88 \%$ cases it was the only manifestation suggesting kraits bites and again indicating strongly high prevalence of kraits in this region. 2 patients presented with local features of envenomation, 1 associated with haematological features with positive 20 minute whole blood coagulation test indicating the presence of viper. Antivenin was given in $75 \%$ of patients and anaphylaxis was not developed in any case. $25 \%$ patients did not receive antivenin due to unavailability and unaffordibility. Surprisingly 2 of them $(50 \%)$ survived which is yet to be explained. ICU facilities were utilized in 2 patients and 1 improved. All of the non-poisonous bite cases improved with supportive treatment. Mortality in this study is very high (44\%) than other studies in Bangladesh $^{2,10}$ which may be due to delay in admission and initiation of treatment.

\section{Conclusion:}

Snake bites cases are still a serious health problem for us. Many patients are not aware of what to do instantly and not getting initial first aid management. They are spending valuable times before seeking treatment in hospitals and causing fatality. Though incidence of seeking treatment from traditional healers are declining, to adopt proper first aid management including application of tourniquet is still a problem. Serious adverse reaction to antivenin is not very common though the number of study population is too small to comment. Fear of giving antivenin should be alleviated. Larger and more studies are required for improving management of this important but neglected problem.

\section{References:}

1. Brunda G, Sashidhar RB. Epidemiological profile of snakebite cases from Andhra Pradesh using immunoanalytical approach. Indian J Med Res 2007 May;12:661-8.

2. Huq F, Islam MA, Sarker MH, Chowdhury B, Ali MW, Kabir MM. Epidemiology of snake bite in Bangladesh. Bangladesh J Zool 1995;23(1):61-64.

3. Ahsan MF.1998.Country reports for BangladeshHerpetofauna of Bangladesh:present status,distribution and conservation.pp.9-17.In:Biology and Conservation of the Amphibians, Reptiles and their habitats in South Asia.(Anslem de Silva,ed.).(Proceedings of the International Conference on the Biology and Conservation of the Amphibians and Reptiles of South Asia,Sri Lanka,August1-5,1996).Amphibia and Reptile Research Organization of Sri Lanka..

4. Khan M.A.R.1982.Wildlife of Bangladesh:a check list.University of Dhaka,Dhaka.

5. Khan M.A.R.Bangladesher Shap(in Bengali). Dhaka: Bangla Academy Press; 1992

6. Sarker SU, Sarker NJ. Wildlife of Bangladesh(a systemic list). Dhaka:The Rico Printers; 1988.

7. Theakston RDG, Phillips RE, Warrell DA. Envenoming by the common krait (Bungarus Caeruleus) and Srilankan cobra (Naja naja naja) ;efficacy and complications of therapy with Haffkine antivenom. Trans Royal Soc Trop Med Hyg 1990;84:301-8.

8. Premawardhena AP, de Silva CE, Foneska MMD, Guantilake SB, de Silva HJ. Low dose subcutaneous 
adrenaline to prevent acute adverse reactions to antivenom serum in patients bitten by snakes: a randomised placebo controlled trial. British Medical Journal 1999;318:1041

9. Faiz MA, Rashid R, Gafur MA, Chowdhury MNH, Rahman MR, Das KK et al. Observation of 10 fatal cases following snake bite in Chittagong. 1993-1998. Bangladesh J Med. 1999; 10: 30-33

10. Islam QT, Faiz MA, Azhar MA, Ekram ARMS, Alam MT. Snake bite in the northern Bangladesh : a hospital based study of 68 cases. TAJ 1999;12:135-8.

11. Morrison JJ, Pearn JH, Covacevich J, Nixon J (). Can Australians identify snakes? Med J Aust 1983; 2: 66-70.
12. Guidelines for the clinical management of snake bites in the south east asia region. 2005. World Health Organization. Written and edited for SEAMEOTROPMED by David A Warrell with contributions by an international panel of experts, first published as a Supplement to the Southeast Asian Journal of Tropical Medicine \& Public Health, Vol 30, Supplement 1, 1999.

13. Faiz MA, Chowdhury SK, Hussain A. Snake bite in Chittagong \& Cox's Bazar- a hospital based study. Bangladesh J Medicine 1997;8:52-57. 